\title{
Deficiência nutricional em plântulas de feijão-de-corda decorrente da omissão de macro e micronutrientes ${ }^{1}$
}

\author{
Nutritional deficiency in cowpea seedlings due to omission of macro and \\ micronutrients
}

Rafael de Souza Miranda ${ }^{2}$, Fabrício Bonfim Sudério ${ }^{3 *}$, Adervan Fernandes Sousa ${ }^{4}$ e Enéas Gomes Filho ${ }^{5}$

\begin{abstract}
Resumo - O feijão-de-corda [Vigna unguiculata (L.) Walp] cv. Pitiúba é uma importante cultura nos âmbitos econômico e social do Nordeste do Brasil, especialmente no Estado do Ceará, que é considerado o maior produtor desta região. Com a finalidade de caracterizar os sintomas de deficiências nutricionais em plântulas de feijão-de-corda, as sementes foram semeadas em areia exaustivamente lavada e, após um período de cinco dias, as plântulas foram transferidas para uma solução nutritiva completa para o período de aclimatação. Após três dias, as plântulas foram submetidas aos diferentes tratamentos. O experimento teve os seguintes tratamentos: solução nutritiva completa $(\mathrm{N} ; \mathrm{P} ; \mathrm{K} ; \mathrm{Ca} ; \mathrm{Mg} ; \mathrm{S}$ e micronutrientes) e omissão individual de cada elemento -N; -P; -K; -Ca; -Mg; -S; -B; -Fe, bem como ausência de aeração. Os sintomas das deficiências foram observados, caracterizados e registrados por fotografias. No final do experimento, as medidas de comprimento e os teores de matérias fresca e seca das raízes e parte aérea das plântulas foram analisados. Todos os macros e micronutrientes causaram sintomas de deficiência e afetaram o desenvolvimento das plântulas. Os sintomas foram desenvolvidos primeiramente em plântulas com carência em Fe, Ca e N. A matéria seca total foi reduzida em todos os tratamentos com ausência de nutrientes. A ausência de $\mathrm{Ca}, \mathrm{N}$ e Fe foi responsável por uma maior redução da biomassa. A ordem decrescente de redução foi a seguinte: $\mathrm{Ca}>\mathrm{N}>\mathrm{Fe}>\mathrm{P}>\mathrm{K}>\mathrm{Mg}>\mathrm{S}>$ Aeração $>\mathrm{B}>$ Completo.
\end{abstract}

Palavras-chave - Hidroponia. Nutrição mineral. Plantas-efeito dos minerais. Sintomas. Vigna unguiculata.

\begin{abstract}
The Cowpea [Vigna unguiculata (L.) Walp] cv. Pitiúba is an important crop in the economic and social contexts in the Northeast of Brazil, especially in the state of Ceará, which is considered the largest producer of this region. With the purpose of characterizing the symptoms of nutritional deficiencies in Cowpea seedlings, the seeds were sowed in washed sand and, after a period of five days, the seedlings were transferred for a complete nutrient solution for the period of acclimatization. After three days, the seedlings were submitted to the different treatments. The experiment had the following treatments: complete nutrient solution (N; P; K; Ca; Mg; S and micronutrients) and individual omission of each element -N; -P; -K; -Ca; -Mg; -S; $-\mathrm{B},-\mathrm{Fe}$ and -aeration. The symptoms of the deficiencies were observed, characterized and registered by pictures. In the end of the experiment, the length measures and the fresh and dry matters of the root and shoot of the seedlings were analyzed. All macro and micronutrients caused deficiency symptoms and they affected the development of the seedlings. The symptoms were developed firstly in seedlings with failure in $\mathrm{Fe}, \mathrm{Ca}$ and $\mathrm{N}$. The total dry matter was reduced in all the treatments with absence of nutrients, but the absence of $\mathrm{Ca}, \mathrm{N}$ and $\mathrm{Fe}$ were responsible for the larger reduction of biomass. The decreasing order of reduction was: $\mathrm{Ca}>\mathrm{N}>\mathrm{Fe}>\mathrm{P}>\mathrm{K}>\mathrm{Mg}>\mathrm{S}>$ Aeration $>\mathrm{B}>$ Complete.
\end{abstract}

Key words - Hydroponia. Mineral nutrition. Plants-effect of minerals. Symptoms. Vigna unguiculata.

\footnotetext{
* Autor para correspondência

${ }^{1}$ Recebido para publicação em 17/04/2009; aprovado em 26/06/2010

Trabalho de pesquisa desenvolvido pelo Curso de Ciências Biológicas da Faculdade de Educação de Crateús/UECE

${ }^{2}$ Programa de Pós-Graduação em Bioquímica, Departamento de Bioquímica e Biologia Molecular, CC/UFC, Fortaleza-CE, Brasil, rafaelmyranda@ hotmail.com

${ }^{3}$ Curso de Ciências Biológicas, Faculdade de Educação de Crateús/UECE, Rua Dr. José Furtado S/N, Prédio do CAIC, Bairro Cidade Nova, CrateúsCE, Brasil, CEP 63.700-000, fsuderio@ig.com.br

${ }^{4}$ Curso de Ciências Biológicas, Faculdade de Educação de Crateús/UECE, Crateús-CE, Brasil, adervansousa@yahoo.com.br

${ }^{5}$ Laboratório de Fisiologia Vegetal, Departamento de Bioquímica e Biologia Molecular, CC/UFC, Fortaleza-CE, Brasil, egomesf@ufc.br
} 


\section{Introdução}

A planta de feijão-de-corda [Vigna unguiculata (L.) Walp.] é anual e apresenta adaptabilidade às condições de estiagem prolongada e capacidade de se desenvolver em solo de baixa fertilidade. A escolha dessa cultura para a realização desse trabalho foi devido à sua importância sócio-econômica no Ceará e no Brasil. No entanto, o cultivo dessa espécie ainda é feito de forma rudimentar e a produtividade média no semi-árido brasileiro é muito baixa (MENDES et al., 2007).

A deficiência de elementos minerais essenciais é comum e provoca desequilíbrios no metabolismo das plantas, fazendo-as apresentar sintomas - expressões da desordem metabólica - característicos (TAIZ; ZAIGER, 2004). Contudo, o fornecimento de adubos minerais de forma adequada e equilibrada para o feijoeiro poderá contribuir não só para a produtividade, mas também para melhorar o valor nutricional do feijão (TEIXEIRA, 2000). Vale ressaltar ainda que a aeração dos solos é importante para a absorção dos nutrientes pela planta, pois esta depende de energia metabólica (ATP) originada na respiração de raízes, a qual depende da taxa de difusão de $\mathrm{O}_{2}$ no substrato. Portanto, a falta de aeração dos solos afeta o comportamento fisiológico das plantas (TAIZ; ZEIGER, 2004).

A ausência de elementos essenciais pode ser diagnosticada, sendo visualmente percebida nas folhas, embora a produtividade já possa estar comprometida, mesmo antes da sua evidência (GONÇALVES et al., 2006). Entretanto, o diagnóstico de problemas nutricionais mediante a observação de sintomas tem grande importância prática por permitir que sejam feitas as correções das deficiências no próximo cultivo (SILVA; FALCÃO, 2002). Vale ressaltar que para algumas condições, como por exemplo, no caso de micronutrientes, a aplicação via foliar durante o ciclo em que foi detectada a deficiência pode mitigar o efeito negativo na produtividade.

Há vários trabalhos referentes ao diagnóstico de sintomas decorrentes da deficiência nutricional em diversas espécies vegetais, tais como: Lima Filho e Malavolta (1997), em estévia (Stevia rebaudiana); Salvador et al. (1999), em goiabeira (Psidium guajava); Silva e Falcão (2002), em pupunheira (Bactris gasipaes); Batista et al. (2003), em gravioleira (Annona muricata); Sarcinelli et al. (2004), em Acacia holosericea; Viégas et al. (2004), em Camucamuzeiro (Myrciaria dúbia); Lange et al. (2005) em mamoneira (Ricinus communis); e Gonçalves et al. (2006), em umbuzeiro (Spondias tuberosa). No entanto, poucos estudos são direcionados à análise da deficiência nutricional em plantas de feijão. Alguns trabalhos analisaram certos aspectos relacionados à nutrição do feijoeiro (AMBROSANO et al., 1996;
ANDRADE et al., 2004; ARF et al., 2004; CAMACHO et al., 1995). Contudo, alguns desses trabalhos citados não foram realizados em condições de hidroponia e todos eles analisaram plantas de Phaseolus vulgaris. Sousa et al. (2007) utilizaram plantas de Vigna unguiculta em suas análises, mas nesse trabalho, os autores avaliaram o crescimento e a nutrição do feijão-de-corda em função da salinidade e observaram que a composição iônica da água de irrigação influenciou os teores de nutrientes minerais.

Portanto, os objetivos deste trabalho foram caracterizar os sintomas causados pela deficiência de macro e micronutrientes, avaliando também a produção de biomassa e o crescimento nessas condições de carência nutricional, bem como na ausência de aeração em plântulas de feijão-de-corda sob condições hidropônicas.

\section{Material e métodos}

O experimento foi realizado na Universidade Estadual do Ceará - UECE, em parceria com o Centro Vocacional Tecnológico (CVT) - Crateús, de março a abril de 2007. O delineamento experimental foi em blocos ao acaso, com três repetições e dez tratamentos: solução nutritiva completa (N; P; K; Ca, Mg, S e micronutrientes) segundo Hoagland e Arnon (1950) e omissão individual de nitrogênio, fósforo, potássio, cálcio, magnésio, enxofre, boro e ferro, sendo a parcela constituída de uma planta por vaso de 3,5 L. O meio pelo qual se conduziu o experimento foi o cultivo hidropônico em casa de vegetação. Para caracterizar os efeitos da falta de aeração, plantas crescendo em solução nutritiva completa foram deixadas sem aeração.

As sementes de feijão-de-corda foram semeadas em areia grossa lavada com água destilada. Após cinco dias da semeadura, as plântulas foram submetidas a um período de aclimatação em solução nutritiva completa a 50\% da força iônica, durante três dias. Em seguida, as plantas foram selecionadas por uniformidade e feita a aplicação dos tratamentos, com trocas semanais de soluções durante 21 dias de condução do experimento. A evolução dos sintomas de deficiência dos elementos nutrientes foi descrita e fotografada desde o estágio inicial até o momento em que os mesmos tornaram-se bem definidos.

Quando os sintomas de deficiência se apresentaram bem evidentes, procedeu-se a coleta e mediu-se o comprimento $(\mathrm{cm})$ das plantas. Para a medição da área foliar foi tomada por base uma folha completamente expandida do segundo ramo das plântulas. Então, foram medidos o comprimento e a largura da folha em centímetros (cm), calculando-se a área foliar (Af) pela seguinte fórmula: Af $=($ comprimento $x$ largura da folha $) / 2$. 
O material colhido foi dividido em raízes, caule e folhas, obtendo-se a massa da matéria fresca. Em seguida, os órgãos foram acondicionados em sacos de papel e colocados em estufa a $65^{\circ} \mathrm{C}$, até atingir massa constante, determinando-se as massas ( $\mathrm{g}$ ) secas das raízes, e caules + folhas. A relação de matéria seca parte aérea: raiz (PA/R) foi calculada por meio da divisão da massa da matéria seca da parte aérea (caule + folhas) pela da raiz. $\mathrm{O}$ crescimento relativo (CR) foi determinado segundo Raij (1991) com modificações, utilizando a seguinte fórmula: $\mathrm{CR}=$ (Matéria seca em ausência do nutriente/Matéria seca do controle) x 100

Os dados foram submetidos à análise de variância (teste F) e as médias comparadas pelo teste de Scott Knott a $5 \%$ de probabilidade. O teste de Scott Knott visa a separação de médias de tratamentos em grupos distintos através da minimização da variação dentro e maximização de variação entre grupos. Os resultados são facilmente interpretados devido à ausência de ambigüidade. Desta forma, este procedimento resulta em maior objetividade e clareza (BORGES; FERREIRA, 2003).

\section{Resultados e discussão}

Nesse estudo de deficiência nutricional em plântulas de feijão-de-corda verificou-se que em relação ao comprimento, todos os tratamentos diferiram significativamente do controle. A ausência de Ca foi a que mais reduziu o comprimento das plântulas. As que cresceram nos tratamentos com deficiência de $\mathrm{Fe}$, de B e de aeração não diferiram significativamente entre si e, depois do $\mathrm{Ca}$, foi na ausência desses elementos que o comprimento foi mais afetado. As ausências de $\mathrm{Mg}$; $\mathrm{S}$; P; K e $\mathrm{N}$ foram as que menos causaram danos ao comprimento e, entre as plântulas com deficiências nesses elementos, não houve diferenças significativas (TAB. 1). A redução do comprimento apresentou a seguinte ordem: Controle $<\mathrm{Mg}<\mathrm{N}<\mathrm{P}<\mathrm{K}<\mathrm{S}<\mathrm{B}<$ Aeração $<\mathrm{Fe}<\mathrm{Ca}$.

Com exceção do boro, todas as deficiências nutricionais e a falta de aeração afetaram significativamente a área foliar das plântulas. As deficiências de $\mathrm{Fe}$ e de $\mathrm{N}$ promoveram alterações morfológicas evidentes nas plântulas e reduziram muito a área foliar, não havendo diferenças significativas entre esses dois tratamentos. No entanto, a área foliar das plântulas com deficiência de $\mathrm{Ca}$ foi a que apresentou maior redução (TAB. 1). A ordem de redução foi a seguinte: Controle $<\mathrm{B}<$ sem aeração $<\mathrm{Mg}$ $<\mathrm{S}<\mathrm{P}<\mathrm{K}<\mathrm{N}<\mathrm{Fe}<\mathrm{Ca}$.

Os dados da Tabela 1 mostram que as ausências de $\mathrm{Ca}, \mathrm{N}$ e $\mathrm{Fe}$ foram as que ocasionaram maiores decréscimos na produção de matérias fresca e seca em relação aos demais tratamentos. A ausência de $\mathrm{Mg} ; \mathrm{S} ; \mathrm{K}$ e de aeração afetou em aproximadamente $50 \%$ a produção das matérias fresca e seca das plântulas de feijão. Não houve diferenças significativas entre as matérias frescas das plântulas que cresceram na ausência de boro e as plântulas controle. A redução apresentou a seguinte ordem: Controle $<\mathrm{B}<\mathrm{sem}$ aeração $<\mathrm{S}<\mathrm{Mg}<\mathrm{K}<\mathrm{P}<\mathrm{Fe}<\mathrm{N}<\mathrm{Ca}$. Os resultados foram semelhantes aos encontrados por Gonçalves et al.

Tabela 1 - Valores médios e desvios padrões para o comprimento, área foliar, matéria fresca, matéria seca, relação PA/R e crescimento relativo $(\mathrm{CR})$ das plântulas de feijão-de-corda

\begin{tabular}{lcccccc}
\hline & Comprimento $(\mathrm{cm})$ & Área foliar $\left(\mathrm{cm}^{2}\right)$ & Matéria fresca $(\mathrm{g})$ & Matéria seca $(\mathrm{g})$ & PA:R & CR (\%) \\
\hline Controle & $94,33 \mathrm{a}$ & $32,35 \mathrm{a}$ & $51,21 \mathrm{a}$ & $5,65 \mathrm{a}$ & 3,12 & 100,00 \\
Sem N & $83,56 \mathrm{~b}$ & $8,24 \mathrm{f}$ & $9,19 \mathrm{~d}$ & $0,75 \mathrm{e}$ & 1,18 & 13,27 \\
Sem P & $83,03 \mathrm{~b}$ & $17,45 \mathrm{~d}$ & $20,70 \mathrm{c}$ & $1,54 \mathrm{~d}$ & 1,33 & 27,26 \\
Sem K & $80,73 \mathrm{~b}$ & $15,35 \mathrm{e}$ & $26,26 \mathrm{~b}$ & $2,51 \mathrm{c}$ & 2,47 & 44,42 \\
Sem Ca & $31,86 \mathrm{~d}$ & $1,52 \mathrm{~g}$ & $2,28 \mathrm{e}$ & $0,26 \mathrm{e}$ & 2,71 & 4,60 \\
Sem Mg & $83,73 \mathrm{~b}$ & $23,14 \mathrm{c}$ & $30,97 \mathrm{~b}$ & $2,76 \mathrm{c}$ & 3,35 & 48,85 \\
Sem S & $75,16 \mathrm{~b}$ & $19,09 \mathrm{~d}$ & $32,21 \mathrm{~b}$ & $2,78 \mathrm{c}$ & 2,81 & 49,20 \\
Sem B & $66,93 \mathrm{c}$ & $29,96 \mathrm{a}$ & $44,68 \mathrm{a}$ & $4,71 \mathrm{~b}$ & 4,01 & 83,36 \\
Sem Fe & $58,76 \mathrm{c}$ & $6,30 \mathrm{f}$ & $9,99 \mathrm{~d}$ & $0,90 \mathrm{e}$ & 3,05 & 15,93 \\
Sem Aeração & $60,53 \mathrm{c}$ & $26,45 \mathrm{~b}$ & $33,91 \mathrm{~b}$ & $3,20 \mathrm{c}$ & 3,20 & 56,64 \\
\hline $\mathrm{F}^{1}$ & $27,29^{* *}$ & $50,73^{* *}$ & $47,66^{* *}$ & $52,69^{* *}$ & - & - \\
$\mathrm{CV}^{2}(\%)$ & 8,31 & 13,96 & 15,14 & 16,46 & - & - \\
\hline
\end{tabular}

Valores médios seguidos da mesma letra, em uma mesma coluna, não diferem entre si pelo teste de Tukey $(P \leq 0,05) ;{ }^{1}$ Valor $F$ do teste de Snedecor; ${ }^{2}$ Coeficiente de variação; **Significativo a $P \leq 0,01$ 
(2006), que estudaram a deficiência de macronutrientes em umbuzeiro (Spondias tuberosa), cuja ordem da redução de matéria seca foi $\mathrm{P}>\mathrm{S}>\mathrm{Mg}>\mathrm{K}>\mathrm{N}>\mathrm{Ca}$.

$\mathrm{Na}$ Tabela 1 observa-se que a relação $\mathrm{PA} / \mathrm{R}$ foi mais afetada em plântulas com omissão de $\mathrm{N}$ e de $\mathrm{P}$, enquanto a ausência de B, aeração, $\mathrm{Mg}, \mathrm{S}, \mathrm{K}, \mathrm{Fe}$ e Ca não promoveram mudanças quando comparadas com as plântulas controle, obedecendo a seguinte ordem: $\mathrm{B}<\mathrm{Mg}<$ sem aeração $<$ Controle $<\mathrm{Fe}<\mathrm{S}<\mathrm{Ca}<\mathrm{K}<\mathrm{P}<\mathrm{N}$.

As plântulas que cresceram com deficiências de aeração, Mg, S, K e B mostraram reduções significativas no crescimento relativo (CR). Contudo, foi na ausência de $\mathrm{P}, \mathrm{N}, \mathrm{Fe}$ e Ca que as plântulas apresentaram menor taxa de CR (TAB. 1). A ordem de redução foi: Controle $<\mathrm{B}<$ sem aeração $<\mathrm{S}<\mathrm{Mg}<\mathrm{K}<\mathrm{P}<\mathrm{Fe}<\mathrm{N}<\mathrm{Ca}$. Estes resultados corroboram com os encontrados por Batista et al. (2003), no qual a deficiência de nitrogênio foi a que mais afetou o $\mathrm{CR}$, obedecendo a seguinte ordem decrescente: Controle $>\mathrm{S}>\mathrm{K}>\mathrm{Mg}>\mathrm{P}>\mathrm{Ca}>\mathrm{N}$.

Os sintomas gerados pela ausência de nitrogênio foram diagnosticados no quarto dia do experimento, sendo caracterizados por uma coloração amarela nas folhas maduras (Figuras 1C e 1D). Como neste trabalho, Lavres Junior et al. (2005) observaram na mamoneira (Ricinus communis L.) que a deficiência do nitrogênio afetou inicialmente as folhas velhas. Por se tratar de um elemento móvel, a redistribuição do $\mathrm{N}$ foi bastante clara, uma vez que as folhas velhas foram as primeiras a apresentarem os sintomas. Com o andamento do experimento, os sintomas tornaram-se mais perceptíveis, observando-se uma clorose generalizada de cor verde amarelada distribuída uniformemente no limbo, no pecíolo e nas nervuras. As raízes se apresentaram pouco desenvolvidas em relação ao tratamento controle, possuindo poucas ramificações e cor amarelada. A Figura 1C mostra, de forma evidente, o resultado da deficiência do nitrogênio no sétimo dia de experimento. Todas as folhas apresentaram coloração verde-pálida e começaram a surgir pigmentos vermelhoarroxeados que se concentraram em manchas irregulares no limbo foliar. No décimo dia do experimento, as plântulas do tratamento sem $\mathrm{N}$ apresentaram raízes com coloração amarelada, poucos pêlos radiculares e poucas ramificações, de modo que se tornaram menos volumosas que aquelas de plântulas controle.

O caule se apresentou fino e ereto com folhas levemente grossas, bem amareladas e com manchas vermelho-arroxeadas bem evidentes. No último dia do experimento, as plântulas apresentavam o mesmo quadro sintomático: sem aumento no crescimento da parte aérea e tendo apenas três ramos foliares, enquanto as plântulas controle apresentavam 14 ramos (FIG. 1D). Além do crescimento reduzido, plântulas deficientes em nitrogênio apresentaram poucas ramificações, com folhas pequenas e amarelecimento generalizado (FIG. 1C e 1D). Sintomas semelhantes foram observados por Santi et al. (2006) em sorgo (Sorghun bicolor (L.) Moench). O desenvolvimento reduzido pode ser explicado devido ao papel desempenhado pelo elemento no metabolismo da planta, já que o nitrogênio é um constituinte de proteínas e ácidos nucléicos, sendo, portanto, essencial para o seu crescimento vegetal (LIMA FILHO; MALAVOLTA, 1997).

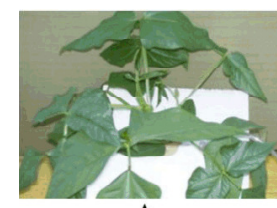

A

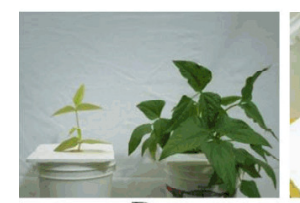

$\mathrm{D}$

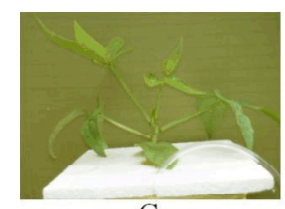

G

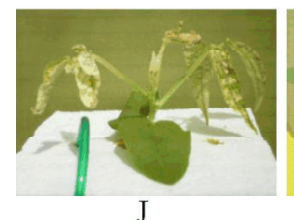

J

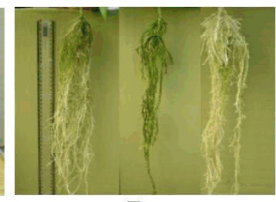

$\mathrm{B}$

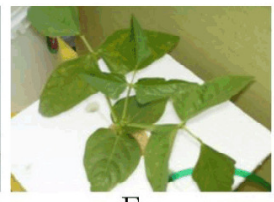

$\mathrm{E}$

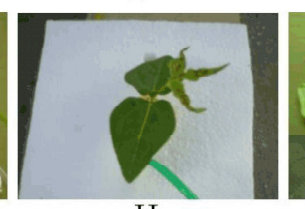

$\mathrm{H}$

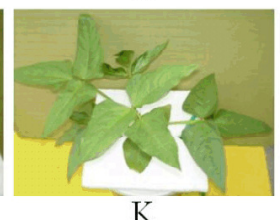

K

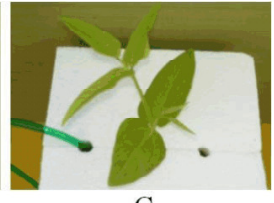

C
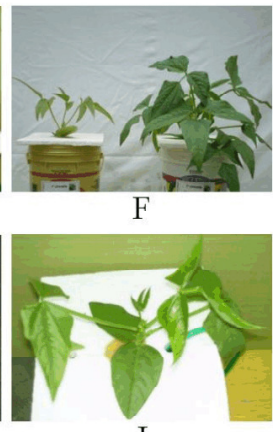

I

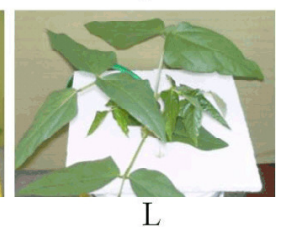

Figura 1 - Parte aérea do feijoeiro desenvolvido no tratamento completo (A); raízes das plântulas dos tratamentos: completo à esquerda, sem boro ao centro e sem aeração à direita (B); sintomas de deficiência de $\mathrm{N}(\mathrm{C})$; desenvolvimento das plantas em ausência de N comparadas com plântulas controle (D); plântula deficiente em $\mathrm{P}$ (E); plântulas de feijão-de-corda em ausência de $\mathrm{P}$ comparadas com o tratamento controle $(\mathrm{F})$; sintomas de deficiência de $\mathrm{K}(\mathrm{G})$; sintomas iniciais de deficiência de $\mathrm{Ca}(\mathrm{H})$; plântula deficiente em $\mathrm{Mg}(\mathrm{I})$; sintomas de deficiência de $\mathrm{S}$ (J); plântula em ausência de B $(\mathrm{K})$; sintomas foliares de deficiência de $\mathrm{Fe}(\mathrm{L})$

A deficiência do fósforo foi diagnosticada no oitavo dia do tratamento. As plântulas submetidas a esse tratamento apresentaram diminuição no crescimento e leve murchamento das folhas mais novas, com bordas recurvadas para cima (FIG. 1E e 1F). As raízes 
apresentaram-se extensas, mas pouco volumosas e com poucas ramificações. As folhas mais velhas apresentaramse com manchas cloróticas verde-limão, evoluindo em direção à base foliar. Com o andamento do experimento, as folhas mais velhas apresentaram clorose por todo o limbo foliar. No décimo quinto dia do experimento, as gemas terminais apresentaram-se dormentes, com redução no crescimento, produzindo apenas quatro ramos foliares (FIG 1E). O caule e as folhas apresentaram-se finos, com crescimento reduzido, semelhante aos resultados encontrados por Batista et al. (2003). A Figura 1F mostra que os ângulos de inserção dos ramos foliares nos caules de plântulas deficientes em fósforo ficaram mais fechados que os da plântula controle (FIG. 1F). Sintomas semelhantes foram encontrados por Gonçalves et al. (2006) e Santi et al. (2006). A ausência de fósforo limitou significativamente o crescimento da parte aérea das plântulas, como se observa na Figura 1F. As raízes apresentaram comprimento próximo da plântula controle, porém com volume diminuído. Constatou-se que as maiores reduções no desenvolvimento das plântulas deficientes em fósforo foram na parte aérea. Isso é importante, pois, implica na maior ou menor produtividade da biomassa. Esse resultado também evidencia a exigência do elemento para as atividades dos meristemas apicais.

Plântulas cultivadas em solução nutritiva na qual o potássio foi omitido apresentaram sintomas visuais com oito dias de tratamento. Inicialmente as folhas maduras apresentaram coloração verde opaco, com pontuações escuras nas nervuras (FIG. 1G). Estes resultados corroboram com os encontrados em goiabeiras (Psidium guajava) por Salvador et al. (1999). A folhagem nova apresentou-se com esverdeamento intenso. No décimo dia do experimento, a parte aérea das plântulas apresentou folhas novas com aspectos deformados e folhas maduras deformadas com manchas cloróticas por todo o limbo foliar (FIG. $1 \mathrm{G}$ ). A exemplo do que ocorreu no trabalho de Silva e Falcão (2002), com punpunheira (Bactris gasipaes), os sintomas de deficiência de $\mathrm{K}$ se agravaram com o tempo, surgiu clorose generalizada nas folhas mais velhas, seguidas por pontuações escuras nas nervuras. No décimo quarto dia, a coloração das folhas se apresentou verde opaco e todas eram deformadas e recurvadas (FIG. 1G). O caule se apresentou bem fino em relação à plântula controle. No último dia do tratamento, plântulas com deficiência de $\mathrm{K}$ apresentaram queda das folhas basais e estabilidade no crescimento. Elas apresentaram cinco ramos foliares, enquanto as plântulas controle apresentaram quatorze ramos, como observado na Figura 1A. As raízes apresentaram-se extensas e associadas a fungos, mas pouco volumosas, quando comparadas às das plântulas controle.

Plântulas crescendo em ausência de cálcio foram as primeiras a manifestarem sintomas característicos. No terceiro dia do experimento, as plântulas apresentaram anormalidades visíveis nas folhas jovens, sendo este um indício da imobilidade do elemento. Inicialmente, as folhas mais novas apresentaram coloração verde-amarelada, com crescimento menor que as folhas da plântula controle. No quarto dia, as bordas das folhas jovens apresentaram-se enrugadas e recurvadas para cima, apresentando pontuações escuras por todo o limbo foliar. A Figura $1 \mathrm{H}$ apresenta as plântulas no quinto dia do experimento, mostrando que as folhas maduras apresentaram-se grossas, quebradiças, com coloração verde, possuindo pontuações escuras por todo o limbo foliar e murchamento nas gemas terminais. As raízes eram grossas, com poucas ramificações e de coloração amarelo escuro. Sintomas semelhantes foram encontrados por Lima Filho e Malavolta (1997), em Estévia [Stevia rebaudiana (Bert.) Bertoni]; Batista et al. (2003) e por Viégas et al. (2004) em Camucamuzeiro (Myrciaria dúbia H. B. K. Mc Waugh). No oitavo dia do tratamento, ocorreu nas plantas deficientes em Ca queda prematura dos ramos foliares jovens, os quais se desprendiam facilmente. Surgiu um novo ramo atrofiado apresentando sinais de clorose. As folhas maduras também apresentaram clorose por todo o limbo foliar, com pontuações pardo-escuras e necrose nas bordas. No décimo dia, as folhas maduras desprenderam-se facilmente do caule. Com a severidade da deficiência, iniciou-se um dessecamento progressivo em toda a estrutura da plântula, levando-a à morte.

Os sintomas da deficiência de magnésio foram observados nas plântulas no nono dia do experimento, havendo uma leve coloração amarela entre as nervuras principais das folhas maduras. A sintomatologia descrita concorda com a observada por Lima Filho e Malavolta (1997); Silva e Falcão (2002) e Gonçalves et al. (2006). $\mathrm{O} \mathrm{Mg}$ é um elemento móvel e sua redistribuição foi comprovada quando se observaram os sintomas da deficiência, inicialmente, nas folhas mais velhas. No décimo dia do experimento, as folhas maduras apresentaram o comprimento maior que a das plântulas controle, porém com largura menor. A Figura 1I mostra que os segundo e terceiro ramos foliares no décimo primeiro dia, apresentaram coloração verde opaco por todo o limbo foliar, com pequena faixa de tecido verde entre as nervuras. No limbo foliar das folhas jovens, com coloração verde intenso, surgiram manchas cloróticas. Com o andamento do experimento os sintomas causados pela deficiência do Mg evoluíram, de modo que as plântulas apresentaram crescimento reduzido, com menos ramos foliares e com caule mais fino que o do tratamento controle. A folhagem, no décimo quinto dia, apresentou-se deformada, com clorose no limbo foliar e as bordas recurvadas para cima. As plântulas apresentaram, ao fim do experimento, caule fino com seis ramos foliares e galhos extensos. Os sintomas de deficiência de $\mathrm{Mg}$ nas raízes só foram diagnosticados nos últimos dias de tratamento, quando apresentaram 
coloração amarela esbranquiçada e comprimento menor e menos volumoso que o do tratamento controle.

Plântulas crescendo em solução nutritiva com ausência de enxofre apresentaram sintomas visuais no décimo primeiro dia do experimento. Inicialmente, o verde foliar das folhas jovens foi de tom mais claro que o observado nas folhas mais velhas, as nervuras apresentaram clorose, sendo mais pálidas que o limbo foliar. As folhas apresentaram-se com espessura fina, textura macia e com crescimento semelhante ao das plântulas controle. As raízes apresentaram coloração escura com crescimento inferior às dos tratamentos controle. Com o andamento do experimento, a clorose presente nas nervuras se estendeu em direção ao limbo das folhas jovens e o ângulo de inserção dos ramos se fechou, ou seja, os ramos se voltaram para cima (FIG. 1J). Sintomas semelhantes foram encontrados por Sarcinelli et al. (2004), em Acacia holosericea. Nesse trabalho, as folhas maduras apresentaram clorose nas bordas e coloração verde pálida. Segundo Viégas et al. (2004), em folhas verdes, a maioria das proteínas está localizada nos cloroplastos e nas moléculas de clorofila. Portanto, plantas deficientes em enxofre apresentam menor teor de clorofila e, conseqüentemente, uma coloração verde pálida. Este é um indício da imobilidade do elemento enxofre, ou seja, a sua não redistribuição pelos órgãos mais velhos, pois os sintomas da deficiência do elemento foram inicialmente caracterizados nos órgãos jovens. A Figura 1J apresenta a plântula no último dia do experimento, as folhas jovens apresentaram-se pequenas, cloróticas, estreitas e com recurvamento das bordas para cima. Os caules dessas plântulas tornaram-se delgados. A quantidade de ramos foi inferior às plântulas controle, com a presença de apenas oito ramos foliares. As raízes apresentaram coloração escura, indicando associações fúngicas e o seu crescimento e volume foram afetados.

A ausência do boro nas plântulas de feijãode-corda provocou sintomas, inicialmente nos órgãos subterrâneos, a partir do décimo dia do experimento. Houve diminuição na taxa de crescimento, engrossamento do caule e produção de ramificações curtas, dando aspecto de espinha de peixe (FIG. 1B). Esta sintomatologia está de acordo com a relatada por Lima Filho e Malavolta (1997). No décimo segundo dia do experimento, as plântulas apresentaram engrossamento do caule e perda da dominância apical, originando brotações laterais com folhas novas cada vez menores (FIG. 1K). Normalmente o B se acumula nas folhas mais velhas, com teores mais altos nas margens. De acordo com Jones Jr. (1970), o transporte deste micronutriente ocorre via transpiração, o que explicaria o fato de os sintomas desta deficiência se manifestarem nos pontos de crescimento. Esse pesquisador constatou que a ausência deste elemento em plantas de milho afetou principalmente os meristemas apicais, ou seja, o crescimento da raiz e da gema terminal. Com o andamento do experimento, as folhas jovens das plântulas de feijão-de-corda que surgiram no sétimo ramo eram retorcidas, atrofiadas, pequenas, grossas, com pontos cloróticos pelo limbo e mostrando ondulações na lâmina foliar. Alguns desses sintomas foram observados em folhas jovens do abacaxizeiro por Ramos et al. (2009). As folhas mais velhas do feijoeiro apresentaramse semelhantes às do tratamento controle. As plântulas com ausência de boro, nos últimos dias de experimento, apresentaram dificuldades em desenvolver novos ramos foliares, pois o botão terminal apresentava grande número de ramos pequenos. No último dia do experimento, os novos ramos das plântulas deficientes em B apresentaramse deformados, com coloração verde intenso. As folhas maduras com coloração verde opaco não foram afetadas significativamente. As raízes das plântulas apresentaram taxa de crescimento bastante reduzido e coloração escura, com poucas ramificações quando comparadas às plântulas controle (FIG. 1B). A taxa de crescimento da parte aérea foi semelhante à observada na plântula controle.

Plântulas crescendo na ausência de ferro apresentaram sintomas semelhantes aos encontrados em mamoneira (Ricinus communis L.), fato descrito por Lange et al. (2005). Os tratamentos com ausência de Fe e de $\mathrm{Ca}$ foram os primeiros a apresentarem sintomas visuais característicos da ausência de cada elemento. No quarto dia de experimento, as plântulas deficientes em $\mathrm{Fe}$ apresentaram coloração amarela por todo o limbo foliar das folhas jovens, enquanto as folhas velhas permaneceram com coloração verde característico de folhas sadias (FIG. 1L). No quinto dia do experimento, pontuações escuras surgiram no limbo das folhas jovens, que se apresentaram deformadas. $\mathrm{O}$ crescimento ficou reduzido quando comparado ao tratamento controle. No sexto dia, surgiram pontos necróticos no limbo das folhas jovens. O limbo das folhas maduras apresentou leves pontuações escuras. Com o andamento do experimento, as folhas jovens apresentaram coloração esbranquiçada, seguida de pontuações necróticas, sendo que as nervuras permaneceram verdes. As folhas maduras apresentaram necrose nas bordas, que evoluíram em direção às nervuras. No botão terminal das plântulas surgiram ramos novos e esbranquiçados, com aspecto deformado e sinais de leve evolução. No décimo dia do experimento, as raízes, com poucas ramificações, mostraram o comprimento e o volume sem sinais de evolução, ou seja, pouco desenvolvidas em relação ao tratamento controle. $\mathrm{O} \mathrm{Fe}$, nos vegetais, normalmente aparece formando um quelato com o ácido cítrico. Seu transporte se dá na corrente transpiratória e no exsudado do xilema. Geralmente, nas plantas em desenvolvimento e nas adultas, praticamente não ocorre redistribuição do Fe. Portanto, os sintomas aparecem primeiro nas folhas novas e, em casos extremos, se tornam esbranquiçadas 
(SILVA; FALCÃO, 2002). Com a severidade da deficiência em $\mathrm{Fe}$, o caule das plântulas se tornou amarelo e fino. As folhas mais velhas apresentaram-se grossas e quebradiças, com necrose no limbo foliar. As nervuras apresentaram pontuações escuras por toda sua extensão. A Figura 1L mostra a plântula no último dia do experimento, apresentando quatro ramos foliares, as folhas maduras apresentavam grande número de pontuações escuras. A folhagem, principalmente dos ramos mais novos, estava esbranquiçada e com manchas necróticas. As folhas eram pequenas, estreitas, deformadas e se desprendiam com um simples toque. O crescimento da parte aérea da plântula foi afetado significativamente, sendo inferior ao observado no tratamento controle (FIG. 1A e 1L). As folhas mais novas apresentavam necrose e caíam facilmente na retirada das plântulas dos tratamentos.

O último aspecto a ser avaliado no experimento foi a ausência de aeração. No décimo terceiro dia, o limbo das folhas novas apresentou-se com coloração verde-intenso, enquanto a folhagem da planta controle apresentou coloração verde. As folhas jovens com espessura fina e textura macia apresentaram crescimento semelhante ao das folhas da plântula controle no último dia do tratamento. A Figura 1B mostra que as raízes das plântulas que cresceram sem aeração apresentaram duas camadas. A camada superior apresentou-se com raízes curtas, grossas e com coloração esbranquiçada e a camada inferior, pouco volumosa, extensa, com poucas ramificações e de coloração branco-amarelada. As plântulas sem aeração apresentaram uma quantidade de ramos foliares (11 ramos) menor que as plântulas controle (14 ramos). A ausência de aeração afetou com maior intensidade a morfologia da raiz, porém, pôde-se evidenciar que afetou tanto a raiz como a parte aérea (FIG 1B e TAB. 1). Na literatura não foram encontrados dados referentes à ausência de aeração em plantas cultivadas por meio hidropônico.

\section{Conclusões}

1. As ausências de N; P; K; Ca; Mg; S; B; Fe e aeração, na solução nutritiva, resultaram em alterações morfológicas, traduzidas como sintomas característicos de deficiência nutricional de cada nutriente na planta de feijão-de-corda;

2. Os primeiros sintomas de deficiência diagnosticados foram nos tratamentos com ausência de ferro e cálcio, seguidos dos de nitrogênio. Ao fim do experimento comprovou-se que esses nutrientes foram os que mais afetaram as atividades metabólicas, prejudicando o desenvolvimento das plântulas;

3. A ausência de Ca foi responsável por um maior prejuízo causado ao desenvolvimento e à produção da biomassa das plântulas. $\mathrm{O}$ enxofre foi o último a manifestar sintomas característicos de sua deficiência pelo feijoeiro.

\section{Referências}

AMBROSANO, E. J. et al. Efeito do nitrogênio no cultivo de feijão irrigado no inverno. Scientia Agrícola, v. 53, n. 02/03, p. 338-343, 1996.

ANDRADE, C. A. B. et al. Produtividade e qualidade nutricional de cultivares de feijão em diferentes adubações. Ciência e Agrotecnologia, v. 28, n. 05, p. 1077-1086, 2004.

ARF, O. et al. Manejo do solo, água e nitrogênio no cultivo de feijão. Pesquisa Agropecuária Brasileira, v. 39, n. 02, p. 131-138, 2004.

BATISTA, M. M. F. et al. Efeitos da omissão de macronutrientes no crescimento, nos sintomas de deficiências nutricionais e na composição mineral de gravioleiras (Annona muricata). Revista Brasileira de Fruticultura, v. 25, n. 02, p. 315-318, 2003.

BORGES, L. C.; FERREIRA, D. F. Poder e taxas de erro tipo I dos testes Scott-Knott, Tukey e Student-Newman-Keuls sob distribuições normal e não normais dos resíduos. Revista de Matemática e Estatística, v. 21, n. 01, p. 67-83, 2003.

CAMACHO, R. et al. Avaliação do estado nutricional do feijoeiro (Phaseolus vulgaris L.) cultivado em solução nutritiva, com variação no fornecimento de N, P e K. Scientia Agrícola, v. 52, n. 03 , p. $422-425,1995$.

GONÇALVES, F. C. et al. Deficiência nutricional em mudas de umbuzeiro decorrente da omissão de macronutrientes. Pesquisa Agropecuária Brasileira, v. 41, n. 06, p. 1053-1057, 2006.

HOAGLAND, D. R.; ARNON, D. I. The water culture method for growing plants without soil. California Agricultural Experimental Station Circular, 1950. 347 p.

JONES JUNIOR, J. B. Distribution of 15 elements in corn leaves. Communications in Soil Science and Plant Analysis, v. 01, n. 01, p. 27-34, 1970.

LANGE, A. et al. Efeitos de deficiência de micronutrientes no estado nutricional da mamoneira cultivar Iris. Pesquisa Agropecuária Brasileira, v. 40, n. 01, p. 61-67, 2005.

LAVRES JUNIOR, J. et al. Deficiências de macronutrientes no estado nutricional da mamoneira cultivar Iris. Pesquisa Agropecuária Brasileira, v. 40, n. 02, p. 141-151, 2005.

LIMA FILHO, O. F.; MALAVOLTA, E. Sintomas de desordens nutricionais em estévia Stevia rebaudiana (Bert.) Bertoni. Scientia Agrícola, v. 54, n. 01/02, p. 53-61, 1997.

MENDES, R. M. S. et al. Relações fonte-dreno em feijãode-corda submetido à deficiência hídrica. Revista Ciência Agronômica, v. 38, n. 01, p. 95-103, 2007.

RAIJ, B. Van. Fertilidade do solo e adubação. Piracicaba: Ceres/Potafos, 1991. 343 p. 
RAMOS, M. J. M. et al. Sintomas visuais de macronutrientes e de boro em abacaxizeiro 'Imperial'. Revista Brasileira de Fruticultura, v. 31, n. 01, p. 252-256, 2009.

SALVADOR, J. O. et al. Efeitos da omissão combinada de N, $\mathrm{P}, \mathrm{K}$ e $\mathrm{S}$ nos teores foliares de macronutrientes em mudas de goiabeira. Scientia Agrícola, v. 56, n. 02, p. 501-507, 1999.

SANTI, A. et al. Deficiência de macronutrientes em sorgo. Ciência e Agrotecnologia, v. 30, n. 02, p. 228-233, 2006.

SARCINELLI, T. S. et al. Sintomas de deficiência nutricional em mudas de Acacia holosericea em resposta à omissão de macronutrientes. Revista Árvore, v. 28, n. 02, p. 173-181, 2004.

SILVA, J. R. A.; FALCÃO, N. P. S. Caracterização de sintomas de carências nutricionais em mudas de pupunheira cultivadas em solução nutritiva. Acta Amazonica, v. 32, n. 04, p. 529-532, 2002.
SOUSA, R. A. et al. Crescimento e nutrição mineral do feijãode-corda em função da salinidade e da composição iônica da água de irrigação. Revista Brasileira de Ciências Agrárias, v. 02, n. 01, p. 75-82, 2007.

TAIZ, L.; ZEIGER, E. Fisiologia vegetal. 3. ed. Porto Alegre: Artmed, 2004. 719 p.

TEIXEIRA, I. R. Respostas do feijoeiro (Phaseolus vulgaris L. cv. Pérola) a diferentes densidades de semeadura e doses de nitrogênio. Ciência e Agrotecnologia, v. 24, n. 02, p. 399-408, 2000.

VIÉGAS, I. J. M. et al. Efeito da omissão de macronutrientes e boro no crescimento, nos sintomas de deficiências nutricionais e na composição mineral de plantas de camucamuzeiro. Revista Brasileira de Fruticultura, v. 26, n. 02, p. 315-319, 2004. 